\title{
Analysis and modelling of the main causes of unsatisfactory quality of transportation infrastructures
}

\author{
F.G. Praticò, A. Astolfi \& R. Fedele \\ DIIES Department, University Mediterranea of Reggio Calabria, Reggio Calabria, Italy
}

\begin{abstract}
Construction process affects the quality of a transportation infrastructure, the development of communities, and the same sustainability of the built environment. Acceptance procedures and regulations are in place, but the resulting quality is sometimes unsatisfactory. This calls for a careful analysis. Based on the above, this study aims at focusing on the key mechanisms and factors that may affect this process and at providing a useful algorithm. The problem has been modelled as a function of one dependent factor, i.e., the profit, and five independent factors, i.e., contract price, pay adjustment, construction costs, bribery, and inefficiency. Each factor has been deeply analyzed, considering main causes of contractor mismanagement, the costs related to a road infrastructure (construction, maintenance and rehabilitation), the methods for deriving penalties, and possible differences emerging from different classes of methods (i.e., empirical and statistical). Results highlight that there are no rational and legal justifications for having unsatisfactory quality of works. The only reasons refer to maliciously and/or inefficiency-related mismanagement, which implies unacceptable buyer's risks, and a paradigm shift towards inconsistency between contractor and citizens' targets. The model here set up is original and can benefit researchers, practitioners, and agencies in assessing the main causes of poor quality works and in setting up effective countermeasures.
\end{abstract}

Keywords: Mismanagement, pay adjustment, poor quality, quality characteristic, quality measure

\section{INTRODUCTION}

Among all the possible causes and conditions of mismanagement, corruption, incompetent or dishonest management of processes (in terms of construction costs reduction due to the use of low-quality materials), and unsatisfactory controls/acceptance procedures are very relevant (Burati et al., 2002a; Bandiera et al., 2009; Praticò et al., 2012, 2013, 2015).

According to literature (Burati et al., 2002; Bandiera et al., 2009; Praticò et al., 2012, 2013, 2015), a contractor's profit mainly depends on (cf. Figure 1A) contractor's expenses (e.g., construction costs), contract price, and pay factors (based on the acceptance plans and monitoring method used, cf. (Praticò and Astolfi, 2017; Fedele et al., 2018). Furthermore, contractor's expectations refer to profit optimization. This latter may derive from having higher pay off, lower penalties, or lower costs (cf., Figure 1B).

Despite the fact that detailed technical specifications and laws are in place, the quality of roads is often unsatisfactory (Howard, 2012), and the motivations behind this study refer to the need to analyze and point out the primary causes that may lead to poor quality work. 

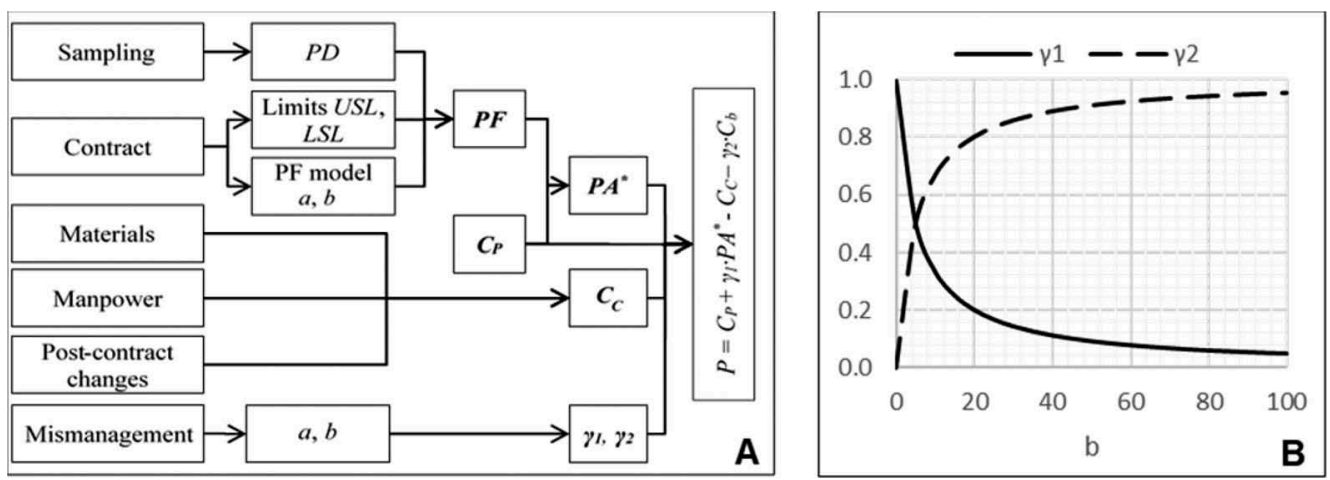

Figure 1. A) From causes to effects; B) Bribery impact.

Symbols. $P D$ : percent defective. $L S L$ : lower specification limit. USL: upper specification limit. PF: Payment Factor. $a$ is the accept/reject factor, $b$ is the bribery level. $P A^{*}$ : generalized pay adjustment. $C_{P}$ : contract price. $C_{C}$ : construction cost. $C_{b}$ : bribe cost (corruption); $\gamma_{1}$ and $\gamma_{2}$ : mismanagement factors that affect contractor profit (cf. Equation 4) $P$ : contractor profit (before taxes).

Consequently, the main objective is to set up a model (herein called P-model) to investigate, study in depth, and quantify the main factors that may cause poor quality work, and to provide recommendations. In order to achieve the objective mentioned above, the following tasks were carried out: Task 1: Set up of the P-model (cf. section 2). This task focused on setting up the new model. Task 2: Simplified model implementation (cf. section 3). A simple application was presented and discussed. Task 3: Detailed model implementation (cf. section 3). In this section, in order to apply the new P-model herein set up, its input PA was derived according to different methods based on the literature.

\section{MODELLING (TASK 1)}

The P-model aims at estimating the dependent variable "contractor's profit", $P$, as a function of several independent variables that, directly or indirectly, affect the road pavement construction process.

The analysis of the literature (in section 1) suggests that contractor profit may be affected by mismanagement. In turn, this latter may depend on the bribery level and/or the inefficiency level (Bandiera et al., 2009).

Let us suppose that the bribery level, $b(0-100)$, and the inefficiency level, $i$ (0-100), impact the profit, $P$, through the following factors (cf. Figure 1B):

$$
\begin{gathered}
\gamma_{1}=\frac{\varepsilon}{\varepsilon+i+b} \text { with } 0 \leq \gamma_{1}<1 \\
\gamma_{2}=\frac{b}{\varepsilon+b} \text { with } 0 \leq \gamma_{2}<1
\end{gathered}
$$

where $\varepsilon>0$ is a factor to calibrate (e.g., $\varepsilon=5$ ), and $\gamma_{1}$ and $\gamma_{2}$ are assumed to be rounded to the first decimal. If there is no bribery $(b=0)$ and no inefficiency $(i=0)$, then the first factor tends to one and the second to zero. In the opposite conditions (high bribery level and inefficiency), the first factor tends to zero while the second tends to one.

In order to derive the profit, $P$, and the profit-to-contract price ratio, $P / C_{P}$, the following expressions are herein set up: 


$$
\begin{gathered}
P=C_{P}-C_{C}+\gamma_{1} \cdot P A^{*}-\gamma_{2} \cdot C_{b} \\
\frac{P}{C_{P}}=\frac{C_{P}-C_{C}}{C_{P}}+\gamma_{1} \cdot \frac{P A^{*}}{C_{P}}-\gamma_{2} \cdot \frac{C_{b}}{C_{P}}
\end{gathered}
$$

where $P$ is the profit $[€], C_{P}$ is the contract price $[€], C_{C}$ is the cost of construction $[€], \gamma_{1}$ is a factor which takes into account the mismanagement level $\left(\gamma_{1}=1\right.$ : correct process; $\gamma_{1} \rightarrow 0$ total misleading in the acceptance process), $P A^{*}$ is the generalized pay adjustment $[€], \gamma_{2}$ is a factor which depends on the bribery level ( $\gamma_{2}=0$, no bribery; $\gamma_{2} \rightarrow 1$ full state of corruption), $C_{b}$ is the bribe cost (due to corruption) [€]. The generalized pay adjustment, $P A^{*}$, is herein defined as:

$$
P A^{*}=a \cdot P A+(-1+a) \cdot\left(C_{C}^{\prime}+C_{M I L}-P A^{\prime}\right)
$$

where $a$ is the accept/reject factor (= 1 acceptance; $=0$ reject), $P A$ is the pay adjustment [€], $C_{C}$ is the cost of reconstruction (in case of reject of the construction, i.e. when $a=0$ ) [€], $C_{M I L}$ is the cost for milling- and landfill-related activities (in case of reject of the construction, i.e. when $a=0$ ) [€], $P A^{\prime}$ is the possible pay adjustment after reject and reconstruction $[€]$.

Note that: 1) If the construction is acceptable $(a=1)$, then $P A^{*}=P A$. 2) If construction is rejected $(a=0)$, then $P A^{*}$ depends on the costs $C_{M I L}$ and $C^{\prime}{ }_{C}$, and on $P A$ '.

Finally, the Payment Factor, $P F$, is given by:

$$
P F=1+P A \%=1+\frac{P A^{*}}{C_{P}}
$$

PA is negative if it relates to penalties and PF is positive and $\leq 1$. Note that the concept of profit equals the concept of surplus, after all expenses (pavement cost) are subtracted from revenue, i.e., contract price plus penalties (Muench and Mahoney, 2001; Willoughby and Mahoney, 2007). Importantly, it differs from the net income, which is the contractor profit after all expenses, including interests and taxes, are subtracted from revenue. Let $g$ be the percentage surplus of $C_{P}$ (contract price) with respect to $C_{C A D}$ (expected, as-design value of $C_{C}$ ):

$$
g=\frac{C_{P}-C_{C A D}}{C_{C A D}}
$$

where $g$ is expected to be around $10 \%$.

The rationale behind the proposed model (Equations 3-7) is that: 1) The profit depends on costs (first term, $C_{C}$ ), penalty-mismanagement interaction (terms with $\gamma_{1}$ and $\gamma_{2}$ ), and contract price, $C_{P}$. 2) To study the reasons of poor/good quality works attention must be focused on how $P$ can be increased through the modification of the terms above (particularly $C_{C}, \gamma_{1}$, and $\left.\gamma_{2}\right)$.

In practice, if the quality measure (i.e., the tool chosen to quantify quality, for example, the percentage within limits, $P W L)$ is lower than the reject quality level $(R Q L$, e.g., 50$)$, then the profit is approximately given by: $P=C_{P^{-}}-2 C_{C^{-}} C_{M I L}$ (corresponding to $P A^{\prime}=0, C_{C} \approx C_{C}^{\prime}, a=$ $0, C_{b}=0, \gamma_{1} \rightarrow 1$ and $\left.\gamma_{2}=0\right)$. If the quality measure is higher than $R Q L(a=1)$, then the profit is given by: $P=-C c+P A+C_{P}$ (with to $P A^{\prime}=0, C_{C} \approx C_{C}, C_{b}=0, \gamma_{1}=1$ and $\gamma_{2}=1$ ). Ideally, the following situations can be given (see Table 1).

Importantly, the factor $\gamma_{1}$, herein introduced, pertains to buyer's and seller's risks. Buyer's risk $(\beta$, risk of accepting a rejectable quality level material) and seller's risk $(\alpha$, risk of rejecting an acceptable quality level material) affect the average value of $\gamma_{1}$. Large samples size would be needed, i.e., 10 to 20 or more (Burati et al., 2002b), to minimize buyer's risk $\beta$. As a matter of fact, if controls (sample size) are maliciously minimized, $\gamma_{1}$ tends to zero (as above) and contractor's profit may be maximized, whatever the quality 
Table 1. Parameters and results of the P-model considering the main possible situations.

\begin{tabular}{|c|c|c|c|}
\hline Situation & Parameters & Result & Eq. \\
\hline Simple acceptance & $\begin{array}{l}a=1 \\
i \rightarrow 0 \\
b=0 \\
\gamma_{1} \rightarrow 1 \\
\gamma_{2}=0 \\
P A=0 \\
C_{C} \approx C_{C A D}\end{array}$ & $\begin{array}{l}P A^{*}=P A=0 \\
P F=1+\frac{P A^{*}}{C_{P}}=1 \\
P=C_{P}-C_{C} \\
\frac{P}{C_{P}} \cong g\end{array}$ & $\begin{array}{l}(8) \\
(9) \\
(10) \\
(11)\end{array}$ \\
\hline $\begin{array}{l}\text { Acceptance with } \\
\text { bonus }\end{array}$ & $\begin{array}{l}a=1 \\
i=0 \\
b=0 \\
\gamma_{1}=1 \\
\gamma_{2}=0 \\
P A>0\end{array}$ & $\begin{array}{l}P A^{*}=P A \\
P F>1 \\
P=-C_{C}+C_{P} \cdot\left(1+\frac{P A}{C_{P}}\right) \\
\frac{P}{C_{P}}=\frac{-C_{C}}{C_{P}}+\left(1+\frac{P A}{C_{P}}\right)\end{array}$ & $\begin{array}{l}(12) \\
(13) \\
(14)\end{array}$ \\
\hline $\begin{array}{l}\text { Acceptance with } \\
\text { penalty }\end{array}$ & $\begin{array}{l}a=1 \\
i \rightarrow 1 \\
b=0 \\
\gamma_{1} \rightarrow 1 \\
\gamma_{2}=0 \\
P A<0\end{array}$ & $\begin{array}{l}P A^{*}=P A \\
P F=1+P A<1 \\
P=C_{P}-C_{C}+\gamma_{1} \cdot P A \\
\frac{P}{C_{P}}=\frac{-C_{C}}{C_{P}}+\left(1+\frac{P A}{C_{P}}\right)\end{array}$ & $\begin{array}{l}(16) \\
(17) \\
(18)\end{array}$ \\
\hline Reject & $\begin{array}{l}a=0 \\
i=1 \\
b=0 \\
\gamma_{1} \rightarrow 1 \\
\gamma_{2}=0\end{array}$ & $\begin{array}{l}P A^{*}=-C_{C}^{\prime}-C_{M I L}+P A^{\prime} \cong-C_{C}^{\prime}-C_{M I L} \\
P F=1+\frac{-C_{C}^{\prime}-C_{M I L}+P A^{\prime}}{C_{P}} \cong 1-\frac{C_{C}^{\prime}+C_{M I L}}{C_{P}}<1 \\
P=C_{P}-C_{C}-C_{C}^{\prime}-C_{M I L}+P A^{\prime} \cong C_{P}-2 C_{C}-C_{M I L} \\
\frac{P}{C_{P}}=1-\frac{C_{C}+C_{C}^{\prime}+C_{M I L}-P A^{\prime}}{C_{P}} \cong 1-\frac{C_{C}+C_{C}^{\prime}+C_{M I L}}{C_{P}} \\
\quad \text { Note that } C_{C}^{\prime} \text { (reconstruction) may be considered the }\end{array}$ & $\begin{array}{l}(20) \\
(21)\end{array}$ \\
\hline $\begin{array}{l}\text { Total } \\
\text { Mismanagement }\end{array}$ & $\begin{array}{l}a=1, i=1 \\
b=1 \\
\gamma_{1} \approx 0, \gamma_{2} \approx 1\end{array}$ & $\begin{array}{l}\text { lowest construction cost that complies with } P A \geq 0 \text {. } \\
\text { In case of total mismanagement }\left(P A^{*} \text { is entirely not }\right. \\
\text { given) } P F>1 \\
P=C_{P} \quad C_{C} \quad C_{b}\end{array}$ & (24) \\
\hline
\end{tabular}

measures are. Finally, note that if $\gamma_{1}=0$ this does not imply that $P>0$. This latter inequality depends on being $C_{P}>C_{C}+C_{b}$, which may be hindered by: 1) Having $C_{P}$ very low due an excessive price cut. 2) Having $C_{P}$ very low due to a design out-of-date. 3) Having excessive $C_{C}$. 4) Having $C_{b}$ too high.

Figure $1 \mathrm{~B}$ above illustrates how $\mathrm{b}$ affects $\gamma_{1}, \gamma_{2}$, and consequently $P / C_{P}\left(C_{b}=0.05 \cdot C_{P} ; \varepsilon=\right.$ 5; $\left.i=0, C_{C}=8, C_{P}=10\right)$.

\section{RESULTS: MODEL IMPLEMENTATION AND VALIDATION (TASKS 2 AND 3)}

\subsection{Simplified model implementation (Task 2)}

In this section the P-model, defined above by the Equations 3-7, was implemented considering a hypothetical and simplified Pay Adjustment, $P A$, based on the percentage between limits, $P W L$, according to a simple $P F$ formula $(P F=55+0.5 \times P W L$, cf. (Burati et al., 2002b; Praticò, 2007).

Table 2 reports the results of this task, which was carried out considering the five situations described in Table 1, where the first four cases are without mismanagement/bribery $(b=0)$, while the fifth case refers to the total mismanagement $(b=100)$. The first case refers to the acceptance with bonus $(b=0)$, where the percentage within limits is $P W L=100 \%$ (very high 
quality) and there is a small bonus (this does not apply to the Italian laws, where bonus is not given).

- The second case refers to the acceptance without where neither penalties nor bonus are given $(b=0)$, and the construction is almost perfect $(P W L=90 \%)$.

- The third case refers to the acceptance with penalty $(b=0)$, where an appreciable part of the construction is defective, $30 \%$, with $P W L=70 \%$. In this case a penalty is given.

- The fourth case refers to the reject vase $(b=0)$, where the quality of the construction is not acceptable, and the reject and reconstruction is enforced to the contractor. This implies a considerable loss of money for the contractor.

- In principle, in terms of construction quality, the fifth case is the same as the fourth one (very low quality, rejection needed), but due to mismanagement (bribery, $b=100$ ), the agency does not enforce the "reject and reconstruct". This could be due to the fact that the agency does not investigate properly about the quality level and does not quantify this occurrence $(P W L=40 \%)$. In this case, the Reject with total mismanagement $(b=100)$ is given. Importantly, the profit is very high.

Table 2. Results of the simplified implementation of the P-model.

\begin{tabular}{llllll}
\hline & $\begin{array}{l}\text { Acceptance } \\
\text { with bonus } \\
(b=0)\end{array}$ & $\begin{array}{l}\text { Simple } \\
\text { acceptance } \\
(b=0)\end{array}$ & $\begin{array}{l}\text { Acceptance with } \\
\text { penalty }(b=0)\end{array}$ & Reject $(b=0) \begin{array}{l}\text { Reject with total mis- } \\
\text { management in a reject } \\
\text { condition }(b=100)\end{array}$ \\
\hline$P W L$ & 100 & 90 & 70 & 40 & 40 \\
$C_{C}\left[\epsilon / m^{2}\right]$ & 10.42 & 10.00 & 9.17 & 7.92 & 7.92 \\
$P A\left[\epsilon / m^{2}\right]$ & 0.625 & 0 & -1.25 & 0 & 0 \\
$C b\left[\epsilon / m^{2}\right]$ & 0 & 0 & 0 & 0 & 0.625 \\
$a[-]$ & 1 & 1 & 1 & 0 & 1 \\
$P A^{*}\left[\epsilon / m^{2}\right]$ & 0.63 & 0.00 & -1.25 & -12.00 & -12.00 \\
$\gamma_{1}[-]$ & 1 & 1 & 1 & 1 & 0 \\
$\gamma_{2}[-]$ & 0 & 0 & 0 & 0 & 1 \\
$P F[-]$ & 1.05 & 1.00 & 0.90 & $\mathrm{R}$ & 1.00 \\
$\boldsymbol{P}\left[\epsilon / m^{2}\right]$ & $\mathbf{2 . 7}$ & $\mathbf{2 . 5}$ & $\mathbf{2 . 1}$ & $-\mathbf{7 . 4}$ & $\mathbf{4 . 0}$ \\
$P / C_{P}[-]$ & $22 \%$ & $20 \%$ & $17 \%$ & $-59 \%$ & $32 \%$ \\
$g[-]$ & $25 \%$ & $25 \%$ & $25 \%$ & $25 \%$ & $25 \%$ \\
\hline
\end{tabular}

Hypotheses and symbols. Calibration factor $=\varepsilon=5$. Inefficiency $=i=0$. As-design (re)construction $\cos t=C_{C A D}=$ $C c^{\prime}=10 € / \mathrm{m}^{2}$. Reconstruction pay adjustment $=P A^{\prime}=0 € / \mathrm{m}^{2}$. Milling cost $=C_{M I L}=2 € / \mathrm{m}^{2}$. Contract price $=C_{P}=$ $12.5 € / \mathrm{m}^{2}$. R=reject. $P W L=$ percent within limits. $C_{C}=$ construction cost. $P A=$ pay adjustment. $C b=$ bribe cost. $P F=$ pay factor. $a=$ accept/reject factor. $P A^{*}=$ generalized pay factor. $\gamma_{1}$ and $\gamma_{2}=$ mismanagement factors.

$P=$ profit. $g=$ percentage surplus.

\subsection{Detailed model implementation (Task 3)}

In this section, the P-model set up above (cf. equations 3-7) was implemented considering several models taken from the literature to derive $P F$ and $P A$. It is important to underline that usually each authority has its own method for calculating penalties and $P A$, which are often a function of measurable quality characteristics (e.g., thickness).

For this reason, the analysis described in this section was carried out by referring to two quality characteristics (i.e., thickness and air void content) and involving a number of methods for penalty estimation, through the following steps:

- Derivation of the effective construction cost $\left(C_{C}\right)$ per investigated layer. This cost is a function of the value of the quality characteristic (e.g., measured characteristic, $A V_{M}$, Burati et al., 2004).

- Definition of quality measure (e.g., Percentage Within Limits, $P W L$ ). 
- Definition of the Acceptable Quality Limit, $A Q L$, and Reject Quality Limit, $R Q L$, for the quality measure.

- Classification of the construction as (1) Acceptable, (2) Acceptable with penalties, and (3) Rejectable.

- Derivation and application of the penalty (e.g., derived through ANAS, 2016, or through Burati et al., 2004).

- Derivation of the actual Payment Factor $(P F)$.

- Derivation of the profit, $P$.

The methods below were applied to two different pavement courses, i.e., open-graded friction courses, OGFC, and dense-graded friction courses, DGFC. Measured thickness $\left(t_{M}\right)$ and measured air voids content $\left(A V_{M}\right)$ were used as quality characteristics (input parameters).

Results of the P-model are presented below in terms of $P F$ (cf. Equation 6) and profit-tocontract price ratio $\left(P / C_{P}\right.$, cf. Equation 4$)$, using to the following methods to derive $P A$ :

1) ANAS's method (AN) (ANAS, 2016).

2) Burati's method (BN) (Burati et al., 2002b).

3) Elyamany-Attia's method (E\&A)(Elyamany, 2013).

4) CIRS's method (CIRS) (Ministero dei Lavori Pubblici, n.d.).

5) Calgary's method (CAL)(Calgary, 2012).

6) Pellinen's method (PM) (Pellinen et al., 2005).

Note that 1) Burati's method was indicated with BN because of the fact that the normal probability density function, N, was used. 2) The method provided by (Pellinen et al., 2005) was adapted to the common as-design values of asphalt concretes, and is herein termed $P M$.

Figure 2 illustrates how $(P F$, Equation 6) and profit $(P$, Equation 4) depend on quality characteristics (i.e., thickness and air void content), based on different methods (e.g., Burati's method), and on sampling variance. In particular, Figures $2 \mathrm{~A}-2 \mathrm{~F}$ refer to nonconformities of measured thickness $\left(t_{M}\right.$; see Figures $2 \mathrm{~A}, 2 \mathrm{C}$ and $\left.2 \mathrm{E}\right)$ and air void content $\left(A V_{M}\right.$; see Figures $2 \mathrm{~B}, 2 \mathrm{D}$ and $2 \mathrm{~F}$ ) for OGFCs, while Figures $2 \mathrm{G}$ and $2 \mathrm{H}$ refer to the same nonconformities for DGFCs. Importantly, $A V_{M}$ variations are due to roller passes.

For each method, Figure 2A shows the Payment Factor ( $P F, \mathrm{y}$-axis) as a function of the measured thickness $\left(t_{M}, \mathrm{x}\right.$-axis) of an OGFC, with a standard deviation of $5 \mathrm{~mm}$. In addition, the Reject Quality Limit $(R Q L)$ is marked with a circle. For example, for $P F_{B N}, R Q L=50$ and corresponds to an average thickness of $41 \mathrm{~mm}$. It can be noted that the maximum $P F$ is obtained when the Burati's method is used, while the minimum $P F$ is given by the Calgary's method.

Figure 2B shows the Payment Factor $(P F)$ as a function of $A V_{M}$ of an OGFC with a standard deviation of $0.5 \%$. In this case, the maximum $P F$ s are provided by the Burati's and the Elyamany-Attia's methods (i.e., $P F_{B N}$ and $P F_{E \& A}$, respectively), while the minimum $P F$ is given by the CIRS's method (i.e., $P F_{C I R S}$ ).

Figure $2 \mathrm{C}$ shows the profit-to-contract price ratio $\left(P / C_{P}\right)$ as a function of the measured thickness $\left(t_{M}\right)$ of an OGFC with a standard deviation of $5 \mathrm{~mm}\left(\gamma_{1}=1, \gamma_{2}=0\right)$. It should be noted that the maximum profit is obtained using Burati's method (i.e, $P_{B N}$ ), and Pellinen's method (i.e., $\left.P_{P M}\right)$. On the contrary, the minimum profit is reached when the Calgary's method is applied (i.e, $P_{C A L}$ ). Note that if $\gamma_{1}=0$ (mismanagement) and $C_{C}>C_{P}$, then $P / C_{P}$ monotonically decreases (if thickness increases; cf. Figure $2 \mathrm{C}$ ). This behavior is critical and may explain a tendency to produce low-quality infrastructures which, in turn, may impact life line performance (Praticò et al., 2012; Marcianò et al., 2015), and how efficient is a nation in providing public services (Bandiera et al., 2009). It seems critical to point out that if $\gamma_{1}=1$ there is a win-win situation (contractor's and dwellers interest superpose, and prefer zone I in Figure 2E), while if $\gamma_{1}=0$ dwellers and contractor's targets are opposite. In Figure 2C, additionally, the $P / C_{P}$ curve for $\gamma_{1}=0$ and $\gamma_{2}=0$ is represented. It refers to the case in which the $C_{C}$ corresponding to the as-design thickness is lower than $C_{P}$. This implies that the lower the thickness is, the higher the $P / C_{P}$ ratio becomes. The case represented refers to $C_{C}=0.8 C_{P}$ (cf., "mismanagement"). 

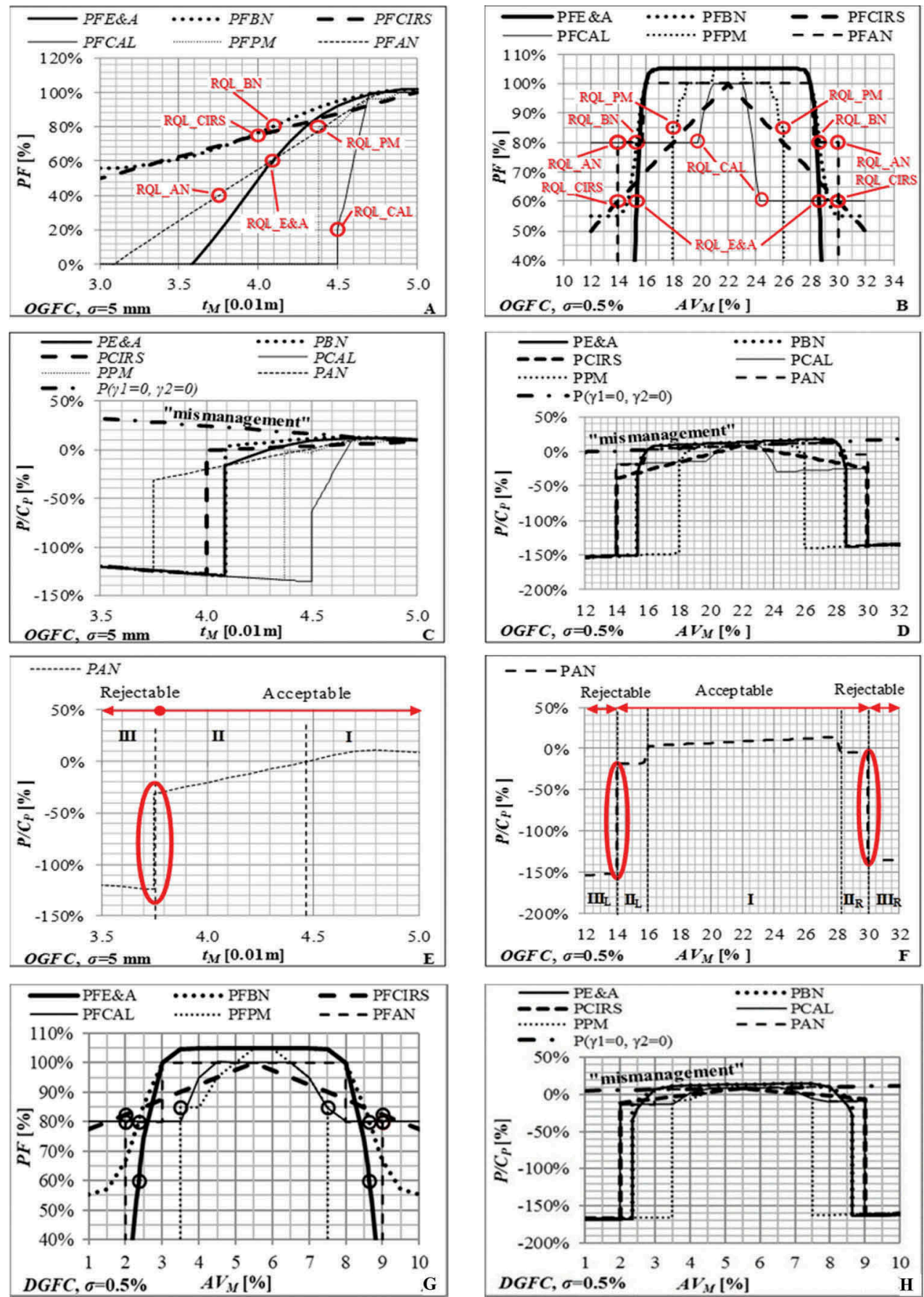

Figure 2. $\quad P F$ vs. thickness (A) and air void (B), $P / C_{P}$ vs. thickness (C) and air void (D), $P / C_{P}$ vs. thickness (E) and air void (F) applying the ANAS's method, $P_{A N}$, for OGFC, and $P F$ vs. air voids (G) and $P / C_{P}$ vs. air voids (H) for DGFC.

Symbols. $t_{M}$ : measured thickness, [cm]; $A V_{M}$ : measured air voids, [\%]; $\sigma$ : standard deviation, [cm]; $C_{P}$ : contract price, $\left[€ / \mathrm{m}^{2}\right] ; P F n$ : Payment Factor, [\%], and $P n$ : profit, [ $\left.€ / \mathrm{m}^{2}\right]$, with $n=\mathrm{E} \& A, \mathrm{BN}, \mathrm{CIRS}, \mathrm{CAL}, \mathrm{PM}, \mathrm{AN}$, which stand for the methods: Elyamany-Attia (2013), Burati (2003, normal distribution), CIRS, The City of Calgary (2012), modified Pellinen (2005) and ANAS (2010), respectively; $P\left(\gamma_{1}=0, \gamma_{2}=0\right)$ : $\mathrm{P}$ in case of "mismanagement" $\left[€ / \mathrm{m}^{2}\right]$ derived using the P-model. 
Figure 2D shows $P / C_{P}$ ratio as a function of $A V_{M}$ of an OGFC reference road pavement with a standard deviation of $0.5 \%$. The behavior of the methods is similar in this case, except for the Pellinen's and the Calgary's methods (i.e., $P_{P M}$ and $P_{C A L}$, respectively). The highest profits can be obtained using the Burati's and the Elyamany-Attia's methods (i.e., $P_{B N}$ and $P_{E \& A}$, respectively). The lowest profit is given by the Calgary's method (i.e., $\left.P_{C A L}\right)$. Note that each $P F$ (or $P / C_{P}$ ) curve may have the following domains (Figure 2E): 1) A first domain, I, in which $P>0$, and there may be the absolute maximum of $P / C_{P}$ (e.g., $45-50 \mathrm{~mm}$ ); 2) A second domain, II, (e.g., $38-45 \mathrm{~mm}$ ) in which $P<0$ but the layer is acceptable and the higher is the thickness, the higher is the profit; 3) A third domain, III, in which $P<0$, the layer is rejectable, but the lower is the thickness, the higher is the profit.

Figure $2 \mathrm{~F}$ shows that in the case of $A V_{M}$ (with $\gamma_{1}=1, \gamma_{2}=0$ ), the three zones almost duplicate $\left(\mathrm{I}, \mathrm{II}_{\mathrm{L}}, \mathrm{III}_{\mathrm{L}}\right.$ and $\mathrm{II}_{\mathrm{R}}, \mathrm{III}_{\mathrm{R}}$, where $\mathrm{L}$ stands for left and $\mathrm{R}$ for right). Importantly, it may happen that $\gamma_{1}=0$ (mismanagement), for example, because of $C_{C}>C_{P}$, and the contractor may decide, for example, to reduce the filler content, having a higher $A V$ (right hand of Figure 2F). Again, this would imply a paradigm shift (zone I to the right side of the plot instead that in the middle).

Figures $2 \mathrm{G}$ and $2 \mathrm{H}$ show $P F$ and $P / C_{P}$ as a function of $A V_{M}$ of a DGFC with a standard deviation of $0.5 \%$. Also in this case, the maximum profits are gained applying the Burati's and the Elyamany-Attia's methods (i.e., $P_{B N}$ and $P_{E \& A}$, respectively), whereas the minimum profit is given by the ANAS's method (i.e., $\left.P_{A N}\right)$. The mismanagement curve $\left(\gamma_{2}>0\right.$, Figure $2 \mathrm{H}$ ) points out two concepts 1 ) Bribery may imply a positive $P / C_{P}$ for a wide range of $A V_{M} ; 2$ ) Situations in which high $A V_{M}$ are caused by local scarcity of fillers (sandy soils), and absence of countermeasures can be easily "tolerated" in case of irregularities in public procurements $\left(\gamma_{I}=0\right)$. Finally, it seems relevant to observe that the relationship between construction costs and $A V_{M}$ depends on the reason of $A V_{M}$ variations.

Figure 3 illustrates how the causes of $A V_{M}$ variation can affect the relationship above. In particular, the reduction of filler percentage (i.e., P200) causes a quasi-linear variation of costs with $A V_{M}$ (the lower filler percentage is, the higher $A V_{M}$ is, and the lower $C_{C}$ is). For roller passes $(N)$, a lower number of roller passes, implies lower $C_{C}$ and generally higher $A V_{M}$. Note that, in each plot, curves intersect at the design point $\left(A V_{M}, C_{C}\right)$, i.e. $22.0 \%, 9.81 € / \mathrm{m}^{2}$ (OGFC, Figure 3A), and 5.5\%, $7.34 € / \mathrm{m}^{2}$ (DGFC, Figure 3B).
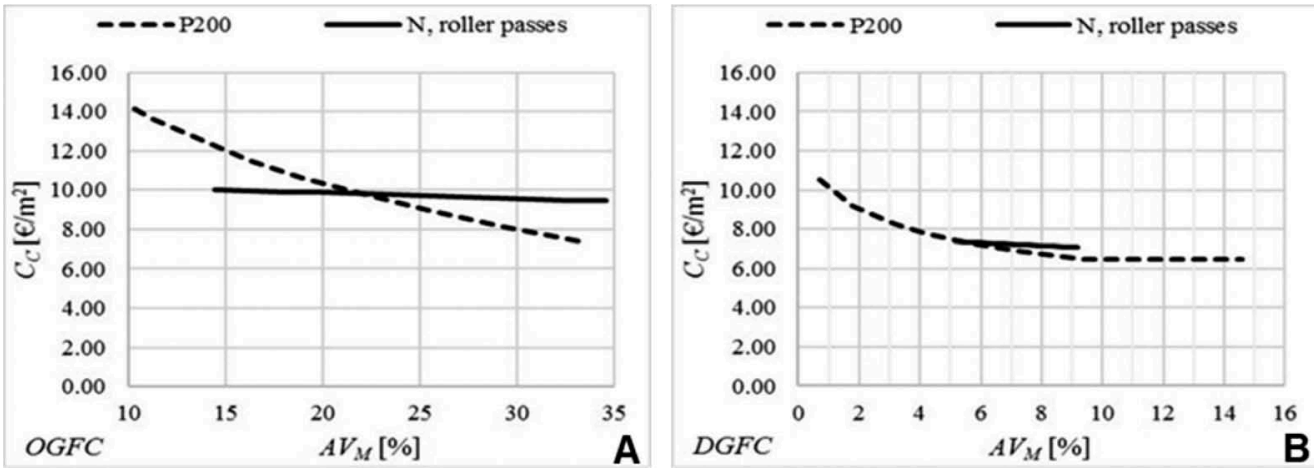

Figure 3. $A V_{M}$ vs. construction cost for OGFC (A), and DGFC (B). Symbols. $C_{C}$ : construction cost; $A V_{M}$ : measured air voids, [\%]; DGFC: dense-graded friction courses; OGFC: open graded friction courses; P200: passing the $0.075 \mathrm{~mm}$ (No. 200) sieve; $N$ : number of roller's passes.

\section{CONCLUSIONS AND RECOMMENDATIONS}

In this study, the primary causes that lead to an unsatisfactory quality of transportation infrastructures were analyzed and an innovative model was setup and implemented to deruve the 
profit. The limitations of the study refer to the lack of data to validate appropriately the method and appear hardly to overcome because of the critical context. This notwithstanding, data available are consistent with the model which provides a realistic tool to approach the problem and try to realistically solve it. The following conclusions can be drawn:

1. Data collected and analyses demonstrate that if quality assurance controls are really carried out, contractor best option still remains to improve process performance and materials quality in order to be enough close to targets and, consequently, to achieve a full compensation (Payment Factor, $P F \geq 1$ ).

2. Indeed, under the hypotheses that acceptance procedures are properly carried out, contractors may optimize their profit if they reduce the variability of product characteristics, and if they better target values (quality characteristics and quality measures) that are close to the limits.

3. In contrast, there are no rational justifications for having quality measures far from being acceptable (unsatisfactory quality of works). The only justification refers to maliciously (bribery level, $b \gg 0$, and bribe costs, $C_{b}>0$ ) and/or inefficiency-related (inefficiency level, $\mathrm{i} \gg 0)$ mismanagement in sampling plans $\left(\gamma_{1} \rightarrow 0\right)$, which implies unacceptable buyer's risks, and a paradigm shift towards inconsistency between contractor and citizens' targets. This point is very crucial and two basic questions here emerge that call for high-level solutions: A) What are the reasons to move towards "mismanagement" (e.g., very low contract prices)?. B) how can contractor mismanagement strategy be (un)successful?

4. To this end, attention should be focused on conflicts of interest between who has to control (e.g., Director) and who is controlled (e.g., Contractor), as per the abovementioned factors $\gamma_{1}$ and $\left.\gamma_{2}\right)$.

Based on the conclusions reported above, the following recommendations can be listed:

- Controlling that contractor and supervisor do not have conflicts of interest.

- Carrying out proper sampling.

- Controlling that supervisors have an outstanding technical and deontological level.

- Having contract specifications very clear, very detailed, and with bonuses: a major push towards a win-win situation for stakeholders: citizens, contractor, and agency.

- Minimizing the mismanagement risks by involving third parties (quality assurance).

Even though results show that contractor can maximize the profit paying attention on product characteristic and limits, future work will be carried out to: 1) Demonstrate that innovative methods for the assessment and the monitoring of the road pavement characteristics can improve the estimation of the penalties. 2) Find and compare other methods for the estimation of the penalties to define the most convenient for both the contractor and the agency.

\section{REFERENCES}

ANAS, 2016. Capitolato Speciale di Appalto - Norme Tecniche per l'esecuzione del contratto - Parte 2.

Bandiera, O., Prat, A., Valletti, T., 2009. Active and passive waste in government spending: Evidence from a policy experiment. American Economic Review 99, 1278-1308. https://doi.org/10.1257/ aer.99.4.1278

Burati, J.L., Weed, R.M., Hughes, C.S., Hill, H.S., Kopac, A., 2002a. Optimal Procedures for Quality Assurance Specifications.

Burati, J.L., Weed, R.M., Hughes, C.S., Hill, H.S., Kopac, A., 2002b. Optimal Procedures for Quality Assurance Specifications.

Calgary, C. of, 2012. Standard Specifications - Roads Construction, City.

Elyamany, A.H., 2013. Using MEPDG to Develop Rational Pay Factor for Hot Mix Asphalt Construction. IOSR Journal of Mechanical and Civil Engineering 10, 30-37. https://doi.org/10.9790/1684-1043037

Fedele, R., Merenda, M., Praticò, F.G., Carotenuto, R., Della Corte, F.G., 2018. Energy harvesting for IoT road monitoring systems. Instrumentation Mesure Metrologie 17, 605-623.

https://doi.org/10.3166/I2M.17.605-623 
Howard, C., 2012. Three Ways Contractors Still Cheat Each Other. Construction Management.

Ministero dei Lavori Pubblici, n.d. CIRS (Centro sperimentale Interuniversitario di Ricerca Stradale). Norme tecniche di tipo prestazionale.

Muench, S.T., Mahoney, J.P., 2001. A Quantification and Evaluation of WSDOT's Hot Mix Asphalt Concrete Statistical Acceptance Specification, Research Project Agreement T9903.2, Task A5 Asphalt Concrete Specifications A.

Pellinen, T.K., Weiss, J., Kuczek, T., Dauksas, G., 2005. Comparison of Various INDOT Testing Methods and Procedures to Quantify Variability in Measured Bituminous and Concrete Properties. https://doi.org/10.5703/1288284313159

Praticò, F.G., 2007. Quality and timeliness in highway construction contracts: A new acceptance model based on both mechanical and surface performance of flexible pavements. Construction Management and Economics 25, 305-313.

Praticò, F.G., Astolfi, A., 2017. A new and simplified approach to assess the pavement surface microand macrotexture. Construction and Building Materials 148, 476-483.

Praticò, F.G., Vaiana, R., Gallelli, V., 2012. Transport and traffic management by micro simulation models: Operational use and performance of roundabouts. In: C. A. Brebbia, J. W. S. Longhurst, W. P. (Ed.), WIT Transactions on the Built Environment. 383-394. https://doi.org/10.2495/UT120331

Praticò, F.G., Vaiana, R., Giunta, M., 2013. Pavement Sustainability: Permeable Wearing Courses by Recycling Porous European Mixes. Journal of Architectural Engineering 19, 186-192. https://doi.org/ $10.1061 /($ asce)ae.1943-5568.0000127

Praticò, F.G., Vaiana, R., Iuele, T., 2015. Macrotexture modeling and experimental validation for pavement surface treatments. Construction and Building Materials 95, 658-666.

Willoughby, K., Mahoney, J.P., 2007. An Assessment of WSDOT's Hot-Mix Asphalt Quality Control and Assurance Requirements. 